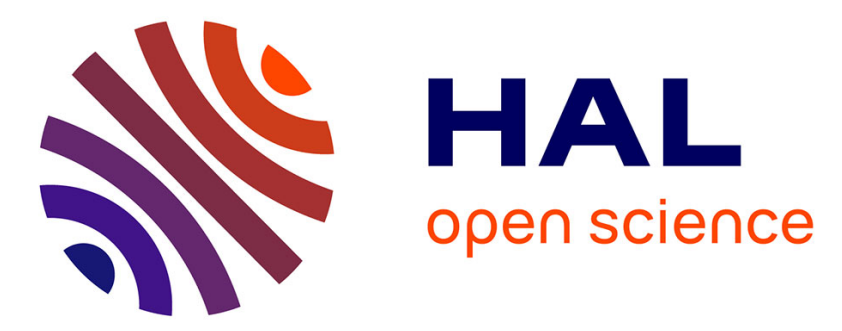

\title{
Magnetic Properties of Epitaxial Fe3O4 Films
}

C. Kleint, M. Krause, R. Höhne, M. Lorenz, H. Semmelhack, A. Schneider, D.

Hesse, H. Sieber, J. Taubert, W. Andrä

\section{To cite this version:}

C. Kleint, M. Krause, R. Höhne, M. Lorenz, H. Semmelhack, et al.. Magnetic Properties of Epitaxial Fe3O4 Films. Journal de Physique IV Proceedings, 1997, 07 (C1), pp.C1-593-C1-594. 10.1051/jp4:19971244 . jpa-00254930

\section{HAL Id: jpa-00254930 https://hal.science/jpa-00254930}

Submitted on 1 Jan 1997

HAL is a multi-disciplinary open access archive for the deposit and dissemination of scientific research documents, whether they are published or not. The documents may come from teaching and research institutions in France or abroad, or from public or private research centers.
L'archive ouverte pluridisciplinaire HAL, est destinée au dépôt et à la diffusion de documents scientifiques de niveau recherche, publiés ou non, émanant des établissements d'enseignement et de recherche français ou étrangers, des laboratoires publics ou privés. 


\title{
Magnetic Properties of Epitaxial $\mathrm{Fe}_{3} \mathrm{O}_{4}$ Films
}

\author{
C.A. Kleint, M.K. Krause, R. Höhne, M. Lorenz, H.C. Semmelhack, A. Schneider, D. Hesse*, H. Sieber*, \\ J. Taubert** and W. Andrä**
}

University Leipzig, Physics Department, Linnéstr. 5, 04103 Leipzig, Germany

* MPIf. Mikrostrukturphysik, Weinberg 2, 06120 Halle, Germany

** IPHT Jena, Helmholtzweg 4, 07743 Jena, Germany

\begin{abstract}
Epitaxial magnetite thin films with (100), (110) and (111) orientation have been deposited by Laser ablation onto substrates with $[\mathrm{NaCl}]$ and [Spinel] structure. X-ray diffraction revealed pseudomorphic growth for $(100)$ and (111) oriented films on $\mathrm{MgO}(100)$ and $\mathrm{ZnFe}_{2} \mathrm{O}_{4}(111)$ respectively, whereas films on $\mathrm{MgAl}_{2} \mathrm{O}_{4}$ showed a high degree of relaxation. For films on $\mathrm{MgAl}_{2} \mathrm{O}_{4}$ and $\mathrm{ZnFe}_{2} \mathrm{O}_{4}$ a significant enhancement of the Verwey-transition temperature compared to bulk material has been observed. The influence of stress on the magnetic anisotropy has been investigated by torque-magnetometry on (110) oriented films. Both films on $\mathrm{MgO}$ and spinel show an [110] in plane easy axis, which can be explained by (tensile) stresses in the case of $\mathrm{MgO}$ but not in the case of spinel. CEMS pattern indicate out of plane components of the magnetisation for all films. We suggest cation antiphase boundaries, observed by TEM to be responsible for this effect, limiting the magnetic coherence length and thus reducing shape anisotropy.
\end{abstract}

\section{INTRODUCTION}

Epitaxial magnetite $\left(\mathrm{Fe}_{3} \mathrm{O}_{4}\right)$ thin films have been prepared by Molecular Beam Epitaxy [1], sputtering [2] and Pulsed Laser Deposition (PLD) [3]. MgO is most often used as a substrate because its low lattice mismatch of $0.3 \%$ allows pseudomorphic growth causing tensile stress in the layer. The epitaxial growth is realised through the fcc oxygen sublattice, inherent in both the $[\mathrm{NaCl}]-$ and the [inverse spinel] structure. It has been found by Conversion Electron Mossbauer Spectroscopy (CEMS), that the magnetisation of $\mathrm{Fe}_{3} \mathrm{O}_{4}$ films has out of plane components. This was attributed to tensile stress, which supports out of plane magnetisation for $(100)$ oriented films [2]. Tension should also introduce a strong $\sin (2 \Theta)$ term to the in plane torque-curves of $(110)$ oriented films on $\mathrm{MgO}$, changing the easy axis to [110], which was indeed observed but with reduced amplitude [2]. The present study was designed to investigate the influence of stress on the magnetic properties of $\mathrm{Fe}_{3} \mathrm{O}_{4}$ thin films using substrates with small and large lattice misfits with both positive and negative signs. Films have been deposited by PLD on $\mathrm{MgO}(100)$ and (110), on (0001) $\mathrm{Al}_{2} \mathrm{O}_{3}$ (c-sapphire) and for the first time on (100) and (110) spinel substrates and (111) growth surfaces of $\mathrm{ZnFe}_{2} \mathrm{O}_{4}$ single crystals [4].

\section{EXPERIMENTAL}

Films of $350-400 \mathrm{~nm}$ thickness have been deposited using a $\mathrm{KrF}$-Eximer-Laser $(\lambda=248 \mathrm{~nm})$ operating at $10 \mathrm{~Hz}$ pulse frequency. $1000 \mathrm{~mJ}$ pulses were focused onto a rotating magnetite target, prepared by standard ceramic methods. The oxygen partial pressure was kept at about $5 \cdot 10^{-7} \mathrm{mbar}$, the substrate temperature was varied between 250 and $600^{\circ} \mathrm{C}$.

\section{RESULTS}

X-ray diffraction revealed pseudomorphic growth for films on (100) $\mathrm{MgO}$ and (111) $\mathrm{ZnFe}_{2} \mathrm{O}_{4}$ (misfit $\leq+0,7 \%$ ), resulting in tensile stress in both cases, whereas for the films on c-sapphire and spinel substrates (misfits $\geq-4 \%$ ) the compressive stress is released for the most part (>95\%). CEMS showed, that the amount of B-site defects can be kept smaller than $0.1 \%$ for substrate temperatures of about $450^{\circ} \mathrm{C}$ for (100) and (111) oriented films, whereas the optimum deposition temperature for (110) films was considerably lower by some $100 \mathrm{~K}$. Transmission electron microscopy on films on $\mathrm{MgO}$ and spinel (100) revealed the existence of cation antiphase boundaries (APB). For these films stacking faults with different (110) fault planes (with spacings between 40 and $150 \AA$ ) have been found, some ending at partial dislocations, most of them forming networks. The characteristic pattern for the (110) oriented films consists of (111) stacking faults, often terminated at small $\mathrm{FeO}$ inclusions (with $\left.\mathrm{a}_{\mathrm{FeO}}>\mathrm{a}_{\mathrm{Fe} 304} / 2\right)$ ), oriented in registry with the layer lattice. The ocurrence of $\mathrm{FeO}$ in (110) oriented layers is somewhat surprising, since the deposition temperature was considerably lower than for the (100) oriented films. 
For the films on $\mathrm{MgO}$ a maximum Verwey-temperature of $122 \mathrm{~K}$ was determined by SQUWD magnetometry (fig.1). The films on spinel substrates showed Verwey-temperatures significantly higher than the bulk value $(\approx 123 \mathrm{~K})$, even for films whith small deviations from stoichiometry, detected by CEMS. Maximum Verwey-temperatures of $127 \mathrm{~K}$ and $132 \mathrm{~K}$ were found for stoichiometric films on (100) and (110) spinel substrates respectively. An even higher transition-temperature of about $135 \mathrm{~K}$ was obtained for the films on $\mathrm{ZnFe}_{2} \mathrm{O}_{4}$ (to our knowledge the highest Verwey-temperature ever observed).

Torque magnetometry was performed on (100) and (110) oriented films on both $\mathrm{MgO}$ and spinel substrates. The in plane measurements on $(100)$ oriented films revealed [110] easy axis due to magnetocrystalline anisotropy, $\mathrm{K}_{1}$ varied between 80 and $90 \%$ of the bulk value at 1T. For (110) oriented films an [110] easy axis was found in agreement with [2]. However the same sin $(2 \Theta)$ behaviour with an even higher amplitude and [110] easy axis was observed for the (110) oriented films on spinel, which cannot be explained by the superposition of magnetocrystalline and stress anisotropy (fig.2). CEMS showed out of plane components of magnetisation for films on $\mathrm{MgO}$ as well as for films on spinel substrates.

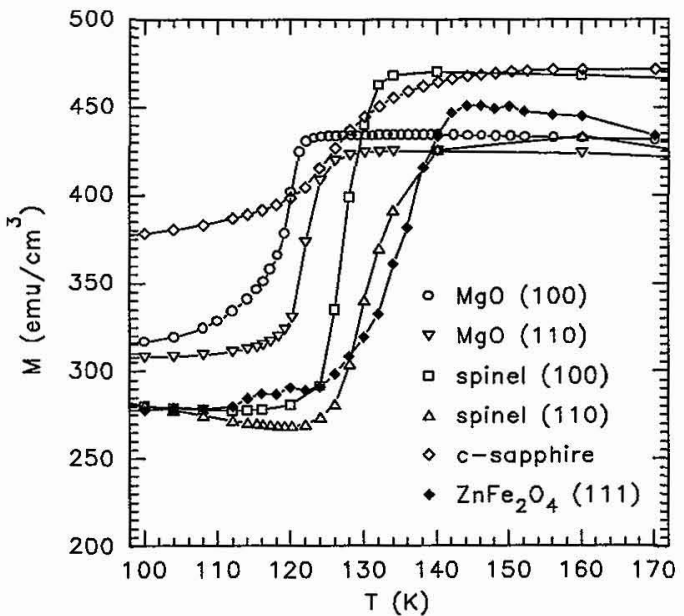

Fig. 1: $\mathrm{ZFC}$ magnetisation curves (in plane, $2 \mathrm{kOe}$ ) for $\mathrm{Fe}_{3} \mathrm{O}_{4}$ films on several substrates

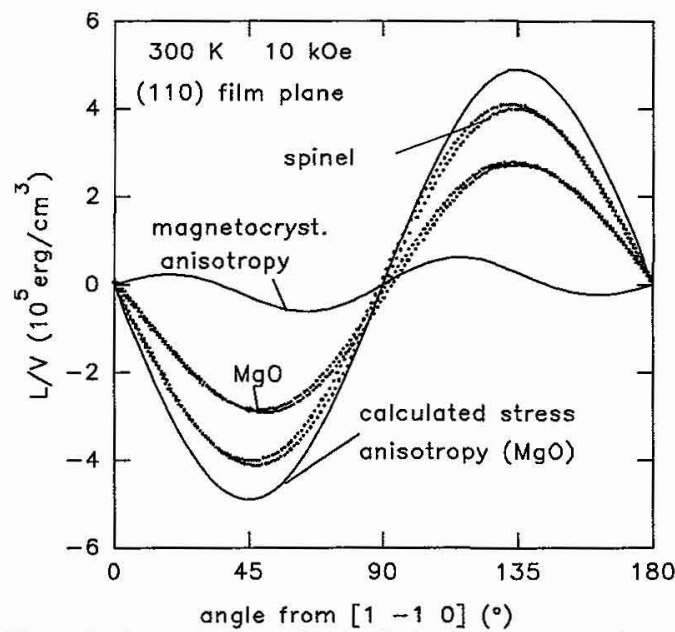

Fig. 2: in plane experimental and calculated torque curves for (110) oriented films on spinel and $\mathrm{MgO}$

\section{CONCLUSIONS}

Magnetite thin films of high epitaxial quality can be grown by PLD on substrates with up to $0.7 \%$ lattice mimatch. The enhancement of the Verwey-Temperature for films on spinel substrates is most probably due to the action of remaining compressive stresses in the film, which are further increased by $\mathrm{FeO}$ inclusions, showing a slightly higher lattice parameter then magnetite. A similar but smaller effect has been observed in $\mathrm{Fe}_{3} \mathrm{O}_{4} / \mathrm{NiO}$-superlattices [1], where the $\mathrm{NiO}$ with its smaller lattice parameter causes in plane compressive stresses in the magnetite layers. Up to now we have no explanation for the high Verwey-temperature of the film on $\mathrm{ZnFe}_{2} \mathrm{O}_{4}$.

The ocurrence of stacking faults is due to the coalescence of various simultanously formed islands during an early stage of growth. Whereas for films on $\mathrm{MgO}$ this is easily understood by the difference in lattice structure, the existence of stacking faults for films on spinel means, that at least in this special case, cation interaction across the interface doesn't play any role for epitaxy. The atomic structure of the APB's provides strong antiferromagnetic $\left(180^{\circ}\right) \mathrm{B}-\mathrm{B}$ interaction (across the fault plane), which is not present in the bulk material. Therefore we suppose the stacking faults to act as sharp domain boundaries, leading to a reduction of the shape anisotropy, which might be the reason for the out of plane components of magnetisation rather then the action of stresses. Though a direct experimental proof of the magnetic action of APB's seems to be complicated, from our point of view for further discussions of the magnetic anomalies of magnetite and other ferrite thin films the existence of APB's should be taken into consideration.

\section{Acknowledgements}

We acknowledge financial support from SMWK. The $\mathrm{ZnFe}_{2} \mathrm{O}_{4}$ single crystals were kindly provided by $\mathrm{Z}$. Li, Argonne.

\section{References}

[1] D.M. Lind, J.A. Borchers, R.W. Erwin, J.F. Ankner et al., J. Appl. Phys. 76 (1994) 6284

[2] D.T. Margulies, F.T. Parker, F.E. Spada, R.S. Goldman et al., Phys. Rev. B 53 (1996) 9175

[3] C.A.Kleint, M. Lorenz, H.C. Semmelhack, M.K. Krause, J.Magn.Magn.Mat. 140-144 (1995) 725

[4] Z. Li, M. Fisher, J.Mat.Sci.Lett. 9 (1990) 759 